\title{
Synthesis, Single Crystal X-ray, Hirshfeld and DFT Studies of 1,8-Dichloro-9,10-dihydro-9,10-ethanoanthracene-11- carboxylic Acid
}

\author{
Mezna Saleh Altowyan ${ }^{1}$, Mujeeb A. Sultan ${ }^{2}$, Saied M. Soliman $\left.{ }^{3}{ }^{(}\right)$, Sammer Yousuf ${ }^{4}$, Israr Ali ${ }^{4}$, Ihab Shawish ${ }^{5}$ \\ and Assem Barakat $6, * \mathbb{D}$
}

check for

updates

Citation: Altowyan, M.S.; Sultan, M.A.; Soliman, S.M.; Yousuf, S.; Ali, I.; Shawish, I.; Barakat, A. Synthesis, Single Crystal X-ray, Hirshfeld and DFT Studies of 1,8-Dichloro-9,10dihydro-9,10-ethanoanthracene-11carboxylic Acid. Crystals 2021, 11, 1161. https://doi.org/10.3390/ cryst11101161

Academic Editor: Ana M. Garcia-Deibe

Received: 1 September 2021

Accepted: 19 September 2021

Published: 24 September 2021

Publisher's Note: MDPI stays neutral with regard to jurisdictional claims in published maps and institutional affiliations.

Copyright: (c) 2021 by the authors. Licensee MDPI, Basel, Switzerland. This article is an open access article distributed under the terms and conditions of the Creative Commons Attribution (CC BY) license (https:/ / creativecommons.org/licenses/by/ $4.0 /)$.
1 Department of Chemistry, College of Science, Princess Nourah bint Abdulrahman University, P.O. Box 84428, Riyadh 11671, Saudi Arabia; msaltowyan@pnu.edu.sa

2 Department of Pharmacy, Faculty of Medical Sciences, Aljanad University for Science and Technology, Taiz 6803, Yemen; mujeeb.AA@just.ac

3 Department of Chemistry, Faculty of Science, Alexandria University, P.O. Box 426, Ibrahimia, Alexandria 21321, Egypt; saied1soliman@yahoo.com or saeed.soliman@alexu.edu.eg

4 H.E.J. Research Institute of Chemistry, International Center for Chemical and Biological Sciences, University of Karachi, Karachi 75270, Pakistan; dr.sammer.yousuf@gmail.com (S.Y.); alii48628@gmail.com (I.A.)

5 Department of General Sciences, Prince Sultan University, P.O. Box 66833, Riyadh 11586, Saudi Arabia; ishawish@psu.edu.sa

6 Department of Chemistry, College of Science, King Saud University, P.O. Box 2455, Riyadh 11451, Saudi Arabia

* Correspondence: ambarakat@ksu.edu.sa; Tel.: +966-11467-5901; Fax: +966-11467-5992

\begin{abstract}
In this paper, synthesis, single-crystal X-ray structure, Hirshfeld and DFT studies of 1,8-dichloro-9,10-dihydro-9,10-ethanoanthracene-11-carboxylic acid are discussed. Different intermolecular contacts affecting the crystal stability are studied using Hirshfeld calculations. The $\mathrm{H}$... Cl and $\mathrm{O}$... H contacts are the most significant, showing corresponding interaction distances of $2.731 \AA$

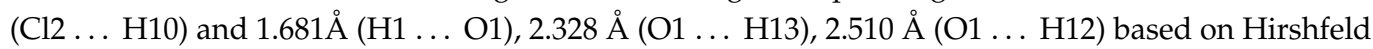
calculations. DFT calculations are carried out to study the electronic behavior, as well as the ${ }^{1} \mathrm{H}$ - and ${ }^{13} \mathrm{C}$-NMR spectra of the synthesized compound. The computed NMR chemical shifts show excellent correlation with the experimental data $\left(\mathrm{R}^{2}=0.9884-0.9705\right)$.
\end{abstract}

Keywords: Anthracenes; ethanoanthracenes; single-crystal X-ray; DFT; Hirshfeld

\section{Introduction}

Anthracene and its derivatives are well-known aromatic hydrocarbons with wide applications, including in organic optoelectronics [1-5], as well as in the pharmaceutical sciences [6-14]. In particular, derivativaization at the $C 9 / C 10$ leads to formation of the ethano-bridge of the anthracene core structures, compounds that are considered significant for development in terms of drug discovery, which have exhibited anti-malarial activities [15,16], anti-multi-drug resistance for cancer [17], anti-depressant properties [18] and high efficacy against cancer treatments $[10,11]$.

In constructing this ethano-bridge of the anthracene-privileged structure, one of the most efficient and powerful protocols is the Diels-Alder reaction. Several representative examples have been reported in the literature regarding their synthesis and applications in different areas. Barton and his team reported on the selectivity of the host behavior of the roof-shaped compounds based on the ethanoanthracene dicarboxylic acids and their derivatives using mixed solvent systems such as ethylbenezene and xylene as guest solutions. The study revealed that these compounds worked selectively as roof-shaped compounds [19].

A recent review reported the development of highly efficient materials for fluid separation in between these studies on anthracene derivatives [20]. Li et al. reported on the 
synthesis and application of europium metal complexes containing an ethanoanthracene derivative as the binding ligand, which proved to have excellent water-quenching-resistant capability [21]. Another reperesntitive example reported by Lane and Capuano involved subsitituted ethanoanthracene, which worked effectively as an allosteric modulator of the dopamine D1 receptor [22].

The synthesis of new molecules and the elucidation of their molecular and supramolecular structures via single-crystal X-ray diffraction analysis are topics of great interest. We have previously studied ethanoanthracenes and published several articles in this field, which have been shown the biological importance of these compounds [23-27]. In this paper, we syntheize and elucidate the molecular and supramolecular structures of 1,8-dichloro9,10-dihydro-9,10-ethanoanthracene-11-carboxylic acid. DFT calculations are performed to predict the spectral (NMR) and electronic properties of the synthesized compound.

\section{Materials and Methods}

\subsection{Synthesisi of 1,8-dichloro-9,10-dihydro-9,10-ethanoanthracene-11-carboxylic acid $\mathbf{5}$}

The precusor 3 was intially prepared following the methodology reported in the literature [18], then precursor 3 was left on the bench to air-oxidize, providing compound 5 (Scheme 1).

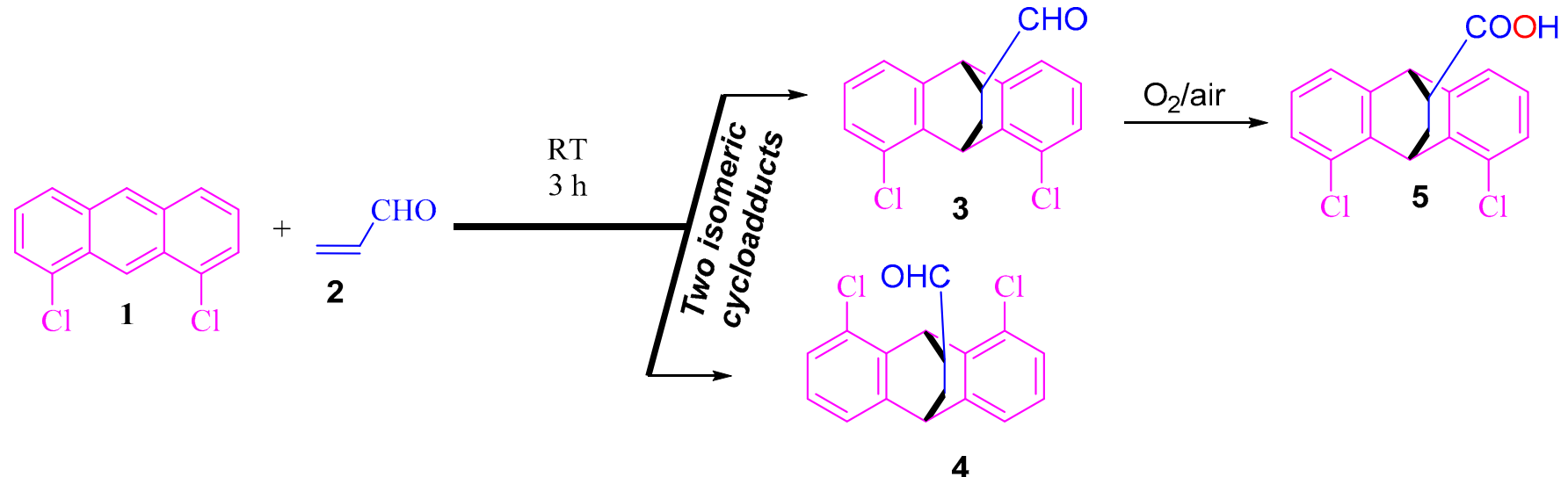

- Bond formation

Scheme 1. Synthesis of 5 .

IR $(\mathrm{KBr}): v=3423,2939,1705,1580,1452,1244,1169,927,772 \mathrm{~cm}^{-1} ;{ }^{1} \mathrm{H}-\mathrm{NMR}$ (DMSO, $500 \mathrm{MHz}): \delta=1.82-1.88(\mathrm{~m}, \mathrm{H}-12,1 \mathrm{H}), 1.97-2.02(\mathrm{~m}, \mathrm{H}-12,1 \mathrm{H}), 2.73-2.77(\mathrm{~m}, \mathrm{H}-11,1 \mathrm{H}), 4.81$ $(\mathrm{d}, J=2.5 \mathrm{~Hz}, \mathrm{H}-10,1 \mathrm{H}), 5.16(\mathrm{t}, J=2.5, \mathrm{H}-9,1 \mathrm{H}), 7.08-7.37(\mathrm{~m}, \mathrm{ArH}, 6 \mathrm{H}) \mathrm{ppm} ;{ }^{13} \mathrm{C}-\mathrm{NMR}$ (DMSO, $125 \mathrm{MHz}$ ): $\delta=28.49$ (C12), 36.48 (C11), 42.95 (C10), 46.67 (C9), 122.82, 124.08, $126.14,126.20,127.22,127.46,127.81,128.24,139.73,139.84,143.04,145.51,173.88 \mathrm{ppm}$.

\subsection{Single-Crystal X-ray Measurements of $\mathbf{5}$}

The full analysis, data collection and refinement protocol is provided in the Supplementary Materials and summary of these details are listed in Table 1.

Table 1. Crystal data for 5.

\begin{tabular}{cc}
\hline & 5 \\
\hline empirical formula & $\mathrm{C}_{17} \mathrm{H}_{12} \mathrm{O}_{2} \mathrm{Cl}_{2}$ \\
fw & 319.17 \\
temp $(\mathrm{K})$ & $293(2)$ \\
$\lambda(\AA)$ & 1.54184 \\
cryst syst & Triclinic \\
space group & $\mathrm{P}-1$ \\
a (̊) & $7.735(2)$ \\
\hline
\end{tabular}


Table 1. Cont.

\begin{tabular}{cc}
\hline & 5 \\
\hline $\mathrm{b}(\AA)$ & $8.0225(12)$ \\
$\mathrm{c}(\AA)$ & $12.0928(16)$ \\
$\alpha(\mathrm{deg})$ & $88.430(14)$ \\
$\beta(\mathrm{deg})$ & $82.549(13)$ \\
$\gamma(\mathrm{deg})$ & $70.46(2)$ \\
$\mathrm{V}\left(\AA^{3}\right)$ & $701.2(3)$ \\
$\mathrm{Z}$ & 2 \\
$\rho_{\text {calc }}\left(\mathrm{Mg} / \mathrm{m}^{3}\right)$ & 1.512 \\
$\mu(\mathrm{Mo} \mathrm{K} \alpha)\left(\mathrm{mm}^{-1}\right)$ & 4.171 \\
$\mathrm{No}$ reflns. & 17655 \\
Unique reflns. & 2534 \\
$\mathrm{GOOF}\left(\mathrm{F}^{2}\right)$ & 1.081 \\
$\mathrm{R}_{\text {int }}$ & 0.0303 \\
$\mathrm{R} 1(\mathrm{I} \geq 2 \sigma)$ & 0.0316 \\
$\mathrm{wR} 2(\mathrm{I} \geq 2 \sigma)$ & 0.0838 \\
$\mathrm{CCDC}$ No. & 2100042 \\
\hline
\end{tabular}

\subsection{Hirshfeld Surface Analysis and Computational Methods}

“Hirshfeld surface analysis was carried out using Crystal Explorer 17.5 [28]. Calculations were performed using the Gaussian 09 software package $[29,30]$ utilizing the B3LYP / 6-31G $(\mathrm{d}, \mathrm{p})$ method. Natural charges were calculated using the NBO 3.1 program as implemented in the Gaussian 09W package [31]. The self-consistent reaction-filed (SCRF) method [32,33] was used to calculate the optimized structure of $\mathbf{5}$ considering the solvent effects (DMSO). Then, the NMR chemical shifts for the protons and carbons were computed using the GIAO method [34]".

\section{Results and Discussion}

\subsection{Chemistry}

According to the literature [18], cycloadducts 3 and $\mathbf{4}$ were obtained as a result of the $\mathrm{BF}_{3}$-OEt ${ }_{2}$-catalyzed Diels-Alder reaction of 1,8-dichloroanthracene $\mathbf{1}$ with acrolein 2 at room temperature. This step was considered to be the most important in the total synthesis of pharmaceutical agents such as maprotiline and benzoctamine [35,36]. The purified carbaldehyde 3 was air-oxidized into its corresponding carboxylic acid 5 .

\subsection{Crystal Structure Description of $\mathbf{5}$}

The molecular structure of 5 is shown in Figure 1. The structure is in agreement with the spectral analyses and confirms the aerobic oxidation of the aldehyde to the corresponding carboxylic acid $\mathbf{5}$. The geometrical parameters for compound $\mathbf{5}$ are broadly similar to those of related 9,10-bridged anthracene derivatives [37-39]. The two chloro-substituted benzene rings (C4-C9), (C1/C2/C11-C14) are both essentially planar (r.m.s. deviations from the leastsquares planes are $0.011 \AA$ and $0.003 \AA$, respectively). The studied anthracene system has a bridge at the positions 9 and 10, while the dihedral angle between these rings is typically $57.21^{\circ}$. The three six-membered rings of the bicyclic core of $5 \mathrm{C} 1 / \mathrm{C} 2 / \mathrm{C} 3 / \mathrm{C} 4 / \mathrm{C} 9 / \mathrm{C} 10$, $\mathrm{C} 3 / \mathrm{C} 4 / \mathrm{C} 9 / \mathrm{C} 10 / \mathrm{C} 16 / \mathrm{C} 15$, and $\mathrm{C} 1 / \mathrm{C} 2 / \mathrm{C} 3 / \mathrm{C} 15 / \mathrm{C} 16 / \mathrm{C} 10$ are all forced into boat form. The carboxylic acid substitution at $\mathrm{C} 16$ shows no unusual features. Table 2 summarizes some of the selected bond angles and bond lengths of the studied compounds. 


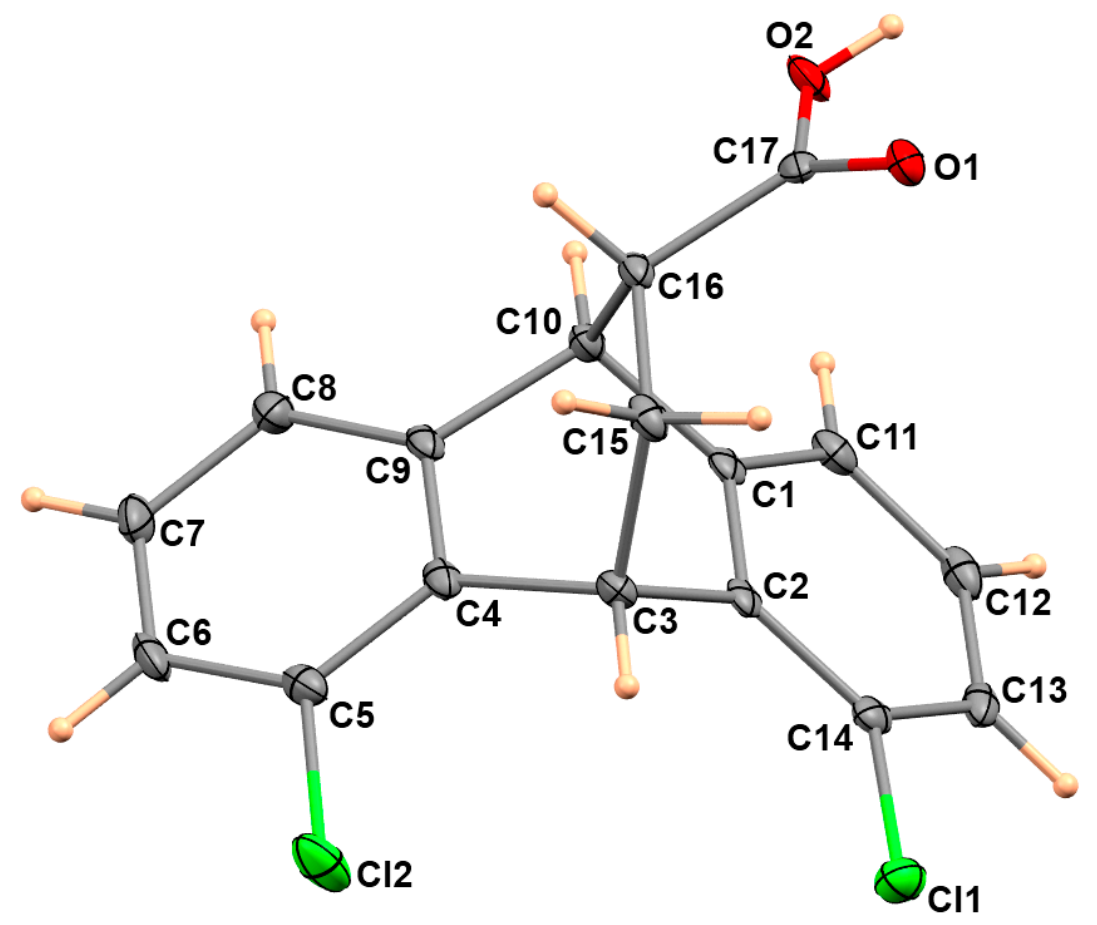

Figure 1. Molecular structure of 5 with anisotropic displacement ellipsoids drawn at the $50 \%$ probability level.

Table 2. Selected bond lengths $[\AA]$ and angles $\left[{ }^{\circ}\right]$ for $\mathbf{5}$.

\begin{tabular}{cccc}
\hline Atoms & Distance & Atoms & Distance \\
\hline C11-C14 & $1.7472(18)$ & C4-C9 & $1.400(2)$ \\
C12-C5 & $1.7386(18)$ & C5-C6 & $1.394(2)$ \\
O1-C17 & $1.223(2)$ & C6-C7 & $1.384(3)$ \\
O2-C17 & $1.320(2)$ & C7-C8 & $1.393(2)$ \\
C1-C11 & $1.386(2)$ & C8-C9 & $1.390(2)$ \\
C1-C2 & $1.403(2)$ & C9-C10 & $1.513(2)$ \\
C1-C10 & $1.516(2)$ & C10-C16 & $1.564(2)$ \\
C2-C14 & $1.384(2)$ & C11-C12 & $1.397(3)$ \\
C2-C3 & $1.515(2)$ & C12-C13 & $1.386(3)$ \\
C3-C4 & $1.517(2)$ & C13-C14 & $1.397(2)$ \\
C3-C15 & $1.559(2)$ & C15-C16 & $1.552(2)$ \\
C4-C5 & $1.385(2)$ & C16-C17 & $1.522(2)$ \\
Atoms & Angle & Atoms & Angle \\
C11-C1-C2 & $121.39(15)$ & C9-C4-C3 & $113.38(14)$ \\
C11-C1-C10 & $125.67(15)$ & C4-C5-C6 & $121.31(16)$ \\
C2-C1-C10 & $112.91(14)$ & C4-C5-C12 & $120.54(13)$ \\
C14-C2-C1 & $118.51(15)$ & C6-C5-C12 & $118.12(13)$ \\
C14-C2-C3 & $127.99(15)$ & C7-C6-C5 & $119.51(15)$ \\
C1-C2-C3 & $113.49(14)$ & C6-C7-C8 & $120.54(16)$ \\
C2-C3-C4 & $106.94(13)$ & C9-C8-C7 & $119.02(16)$ \\
C2-C3-C15 & $106.42(13)$ & C8-C9-C4 & $121.38(15)$ \\
C4-C3-C15 & $106.96(13)$ & & \\
C5-C4-C9 & $118.19(15)$ & & \\
C5-C4-C3 & $128.42(15)$ & & \\
\hline
\end{tabular}

The structure of 5 is stabilized by the three intramolecular hydrogen bonding interactions, C3-H3...Cl1, C3-H3...Cl2, and C15-H15B...O1, with hydrogen-acceptor distances of $2.76,2.78$, and $2.42 \AA$, respectively. The corresponding donor-acceptor distances are $3.211(2), 3.226(2)$, and $2.873(2)^{\circ}$, respectively (Table 3). In addition, its supramolecular structure is controlled mainly by the intermolecular $\mathrm{O} 2-\mathrm{H} 1 \ldots \mathrm{O} 1, \mathrm{C} 10-\mathrm{H} 10 \ldots \mathrm{Cl} 2$, and 
C15-H15B...O1 hydrogen bonding interactions, with donor-acceptor distances of 2.662(2), 3.611(2), and 3.394(2) $\AA$, respectively (Figure 2). The intermolecular O2-H1 ... O1 bonds lead to the formation of centrosymmetric dimers forming the eight-membered ring comprising the atoms $\mathrm{O} 1 \mathrm{C} 17 \mathrm{O} 2 \mathrm{H} 1 \mathrm{O} 1 \mathrm{C} 17 \mathrm{O} 2 \mathrm{H} 1$, as shown in Figure 2.

Table 3. Hydrogen bonds for $5\left[\AA\right.$ and $\left.^{\circ}\right]$.

\begin{tabular}{ccccc}
\hline D-H...A & d(D-H) & d(H...A) & d(D...A) & $<$ (DHA) \\
\hline O2-H1...O1 ${ }^{\text {a }}$ & 0.82 & 2.48 & $2.662(2)$ & 176 \\
C3-H3...Cl1 & 0.98 & 2.76 & $3.211(2)$ & 109 \\
C3-H3..Cl2 & 0.98 & 2.78 & $3.226(2)$ & 108 \\
C10-H10...Cl2 ${ }^{\text {b }}$ & 0.98 & 2.81 & $3.611(2)$ & 140 \\
C13-H13...O1 ${ }^{c}$ & 0.93 & 2.48 & $3.394(2)$ & 168 \\
C15-H15B...O1 & 0.97 & 2.42 & $2.873(2)$ & 108 \\
\hline
\end{tabular}

Note: ${ }^{\mathrm{a}}-\mathrm{x}-\mathrm{y}+2,-\mathrm{z} ;^{\mathrm{b}}-1+\mathrm{x}, \mathrm{y}, \mathrm{z}$ and ${ }^{\mathrm{c}}-\mathrm{x}+1,-\mathrm{y}+1,-\mathrm{z}$.
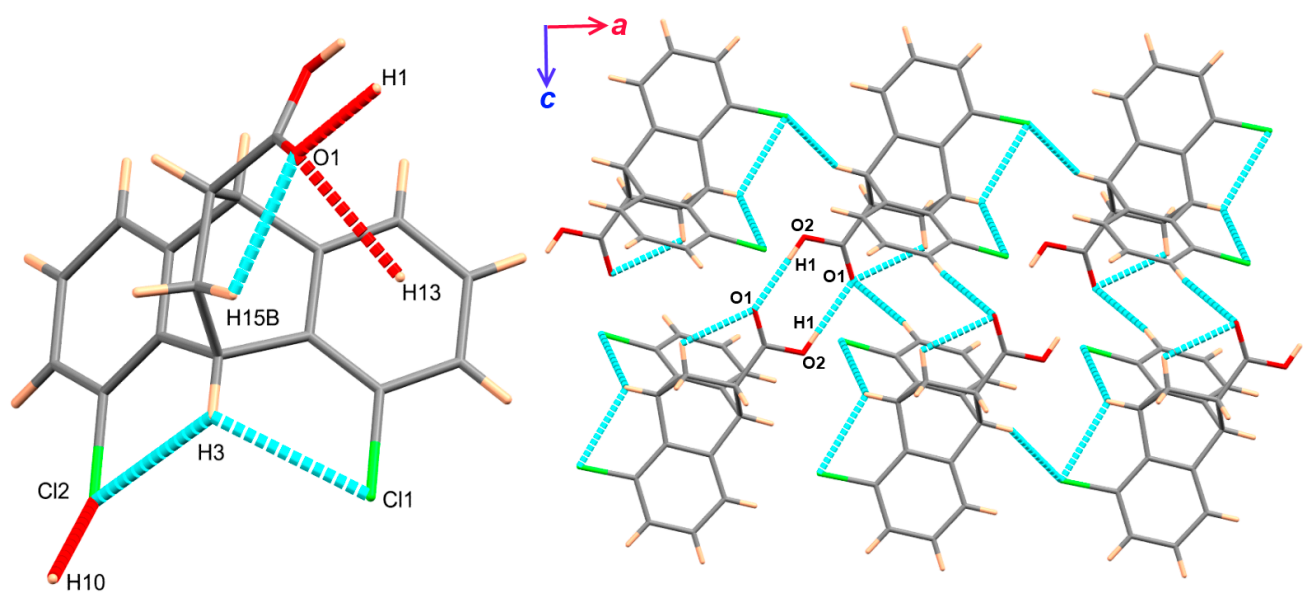

Figure 2. Hydrogen bond contacts (left) and packing of molecular units via hydrogen bonding interactions (right).

\subsection{Analysis of Molecular Packing}

In the solid-state crystalline structure, the molecular units are held together by intermolecular contacts, which have great impact on the crystal stability. In this study, the crystal stability was affected by different intermolecular contacts, which was analysed using Hirshfeld surface analysis (Figure 3 ). In the $d_{\text {norm }}$ map, the short significant contacts appeared as red spots, while the less important intermolecular interactions appeared as blue or white areas. The percentage contributions of each contact were determined based on the decomposition of the fingerprint plot (Figure 4). A summary of the intermolecular contacts is depicted in Figure 5.
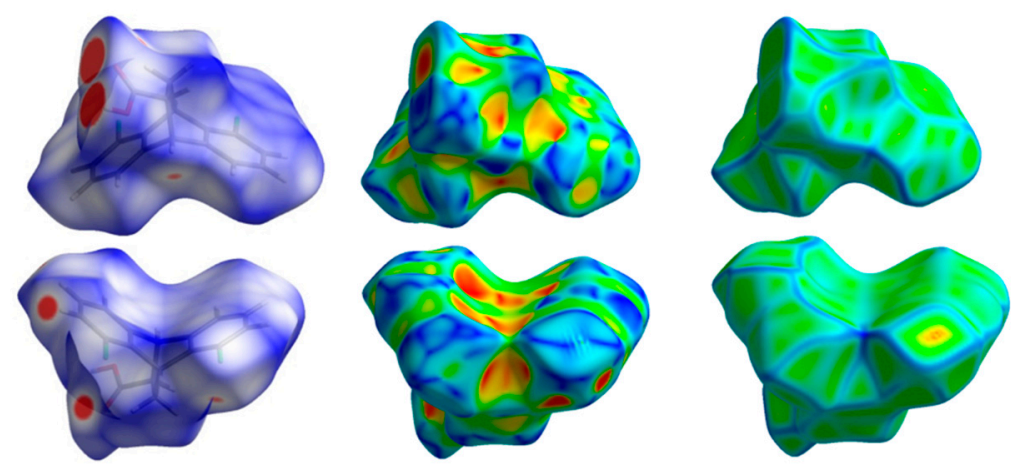

Figure 3. Hirshfeld surfaces of 5 . 

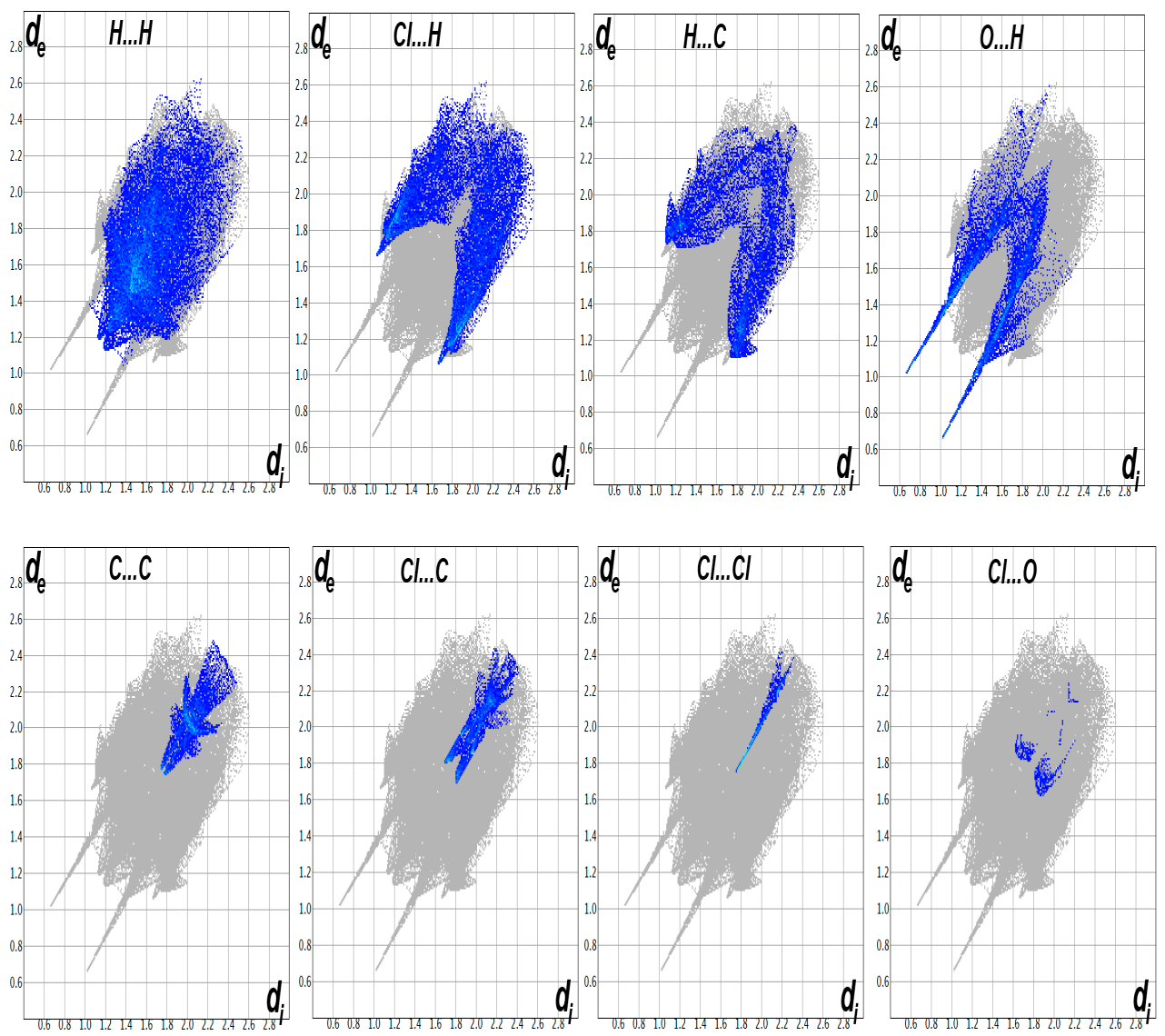

Figure 4. Fingerprint plots for all interactions in 5.

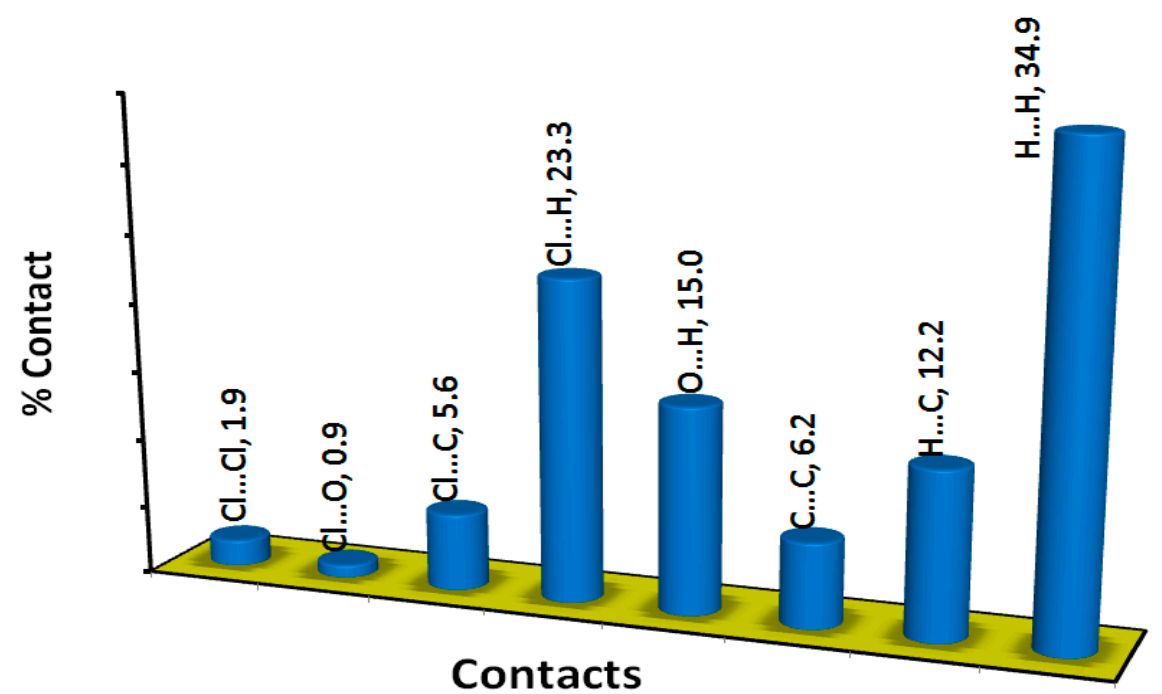

Figure 5. Percentages and intermolecular interaction summary for $\mathbf{5 .}$

In the $\mathrm{d}_{\text {norm }}$ Hirshfeld surface of $\mathbf{5}$, several significant contacts appeared as red regions. These interactions were due to $\mathrm{O} \ldots \mathrm{H}$ and $\mathrm{H} \ldots \mathrm{Cl}$, as shown in Figure 6. The percentages of these interactions were 23.3 and $15.0 \%$, respectively. In addition, these interactions revealed intense staples in the decomposed fingerprint plots, which could be considered another feature of short, significant contacts. The corresponding interaction distances based on the Hirshfeld analysis were $1.681 \AA$ (H1 . . O 1), $2.328 \AA$ (O1 . . H13), $2.510 \AA$ (O1 . . H12), and $2.731 \AA(\mathrm{Cl} 2 \ldots \mathrm{H} 10)$. 


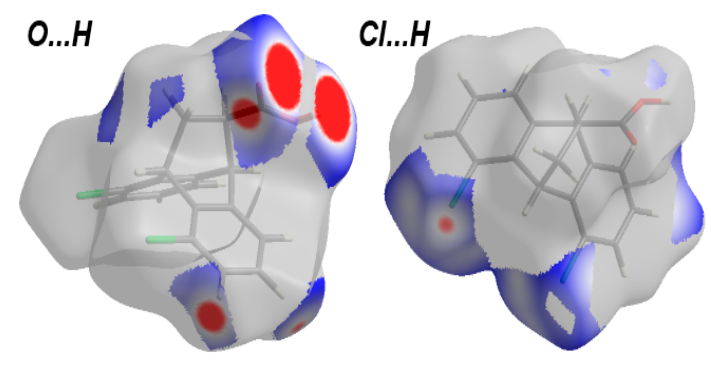

Figure 6. Decomposed $d_{\text {norm }}$ maps of the important interactions in $\mathbf{5}$.

\subsection{DFT Studies}

The structure of 5 is shown in Figure 7A. The structure is overlaid with the results obtained from the single-crystal X-ray analysis, as shown in Figure 7B. Table S1 (Supplementary Materials) shows that the geometric parameters of the studied compound are in harmony between the computed and experimental data. The presence of slight differences may be due to the crystal packing effects. In addition, the relation between the computed and experimental geometric parameters clearly shows the high correlation coefficients for the bond distances $\left(R^{2}=0.9947\right.$; Figure 7C) and angles $\left(R^{2}=0.9644\right.$; Figure 7D).

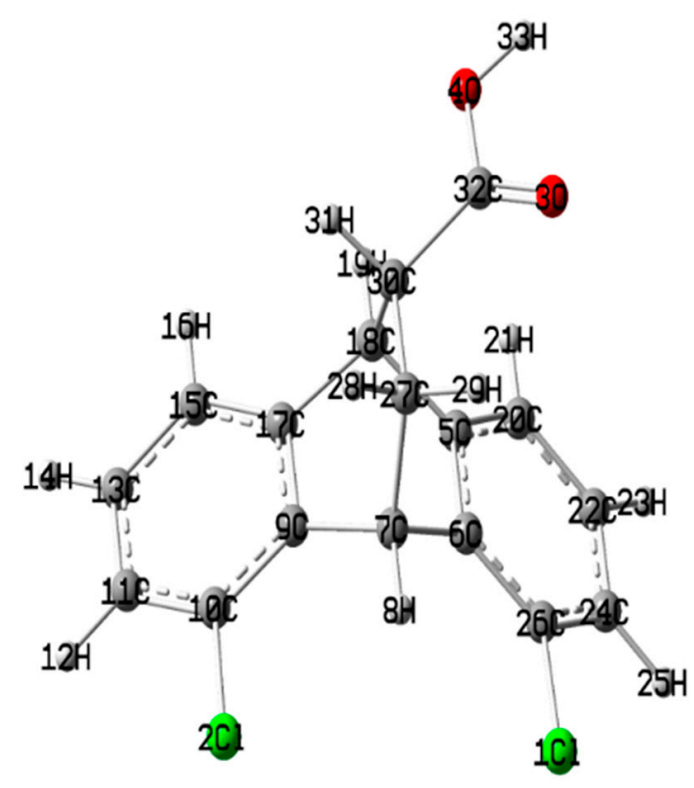

(A)

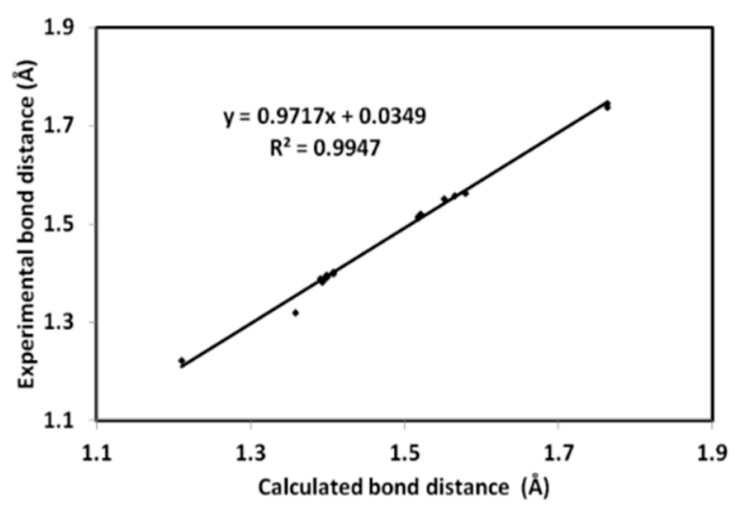

(C)

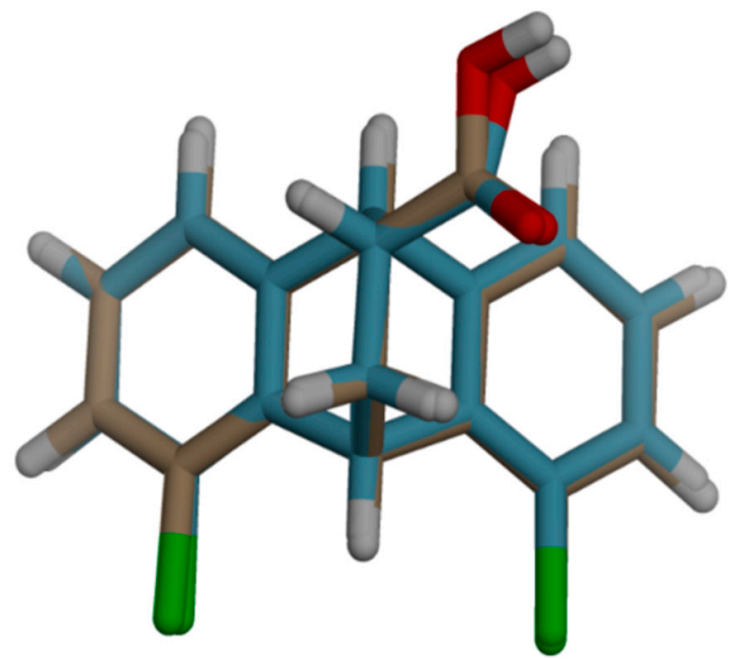

(B)

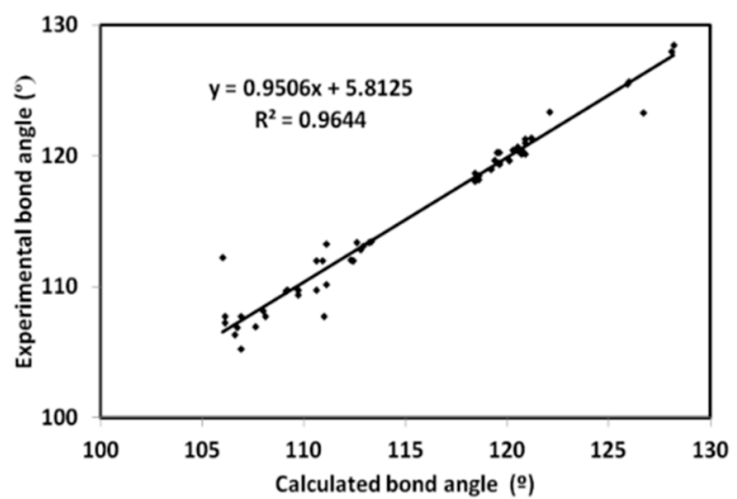

(D)

Figure 7. The optimized structure (A), overlaid with the experimental single-crystal X-ray analysis results, (B) as well as correlation graphs between the calculated and experimental bond distances (C) and angles (D) for 5. 
The natural population analysis was used to calculate the atomic charges at the different atomic sites. The results are presented graphically in Figure 8. The figure shows two slightly negative chlorine atoms with very close natural charges $(-0.0067$ and $-0.0073 \mathrm{e})$. On the other hand, the oxygen atoms of the $-\mathrm{CO}_{2} \mathrm{H}$ group are strongly electronegative, with natural charges of -0.5915 and -0.7223 e for the carbonyl and hydroxyl oxygen atoms, respectively. The carboxylic group has the most electronegative atom and the most electropositive atomic sites, which are the oxygen of the $\mathrm{OH}$ group and carbon atom of the carbonyl group, respectively. The latter has a natural charge of $0.8463 \mathrm{e}$, while the rest of the carbon atoms are electronegative. In contrast, the $\mathrm{OH}$ proton is the most positive hydrogen site, with a natural charge of 0.5059 e. The molecular electrostatic potential (MEP) map shown in Figure 9 reveals the high negative charge density related to the carbonyl oxygen and the high positive charge related to the $\mathrm{OH}$ proton. Additionally, the presence of an intense red region close to the carbonyl oxygen atom and a blue region close to the $\mathrm{OH}$ proton shed light on the most probable hydrogen bond acceptor and donor sites, respectively. These results are in agreement with the observed X-ray structure of the studied system. The calculated dipole moment is 4.2782 Debye, indicating a highly polar molecule, while the direction of the dipole moment vector is presented in the left part of Figure 9.

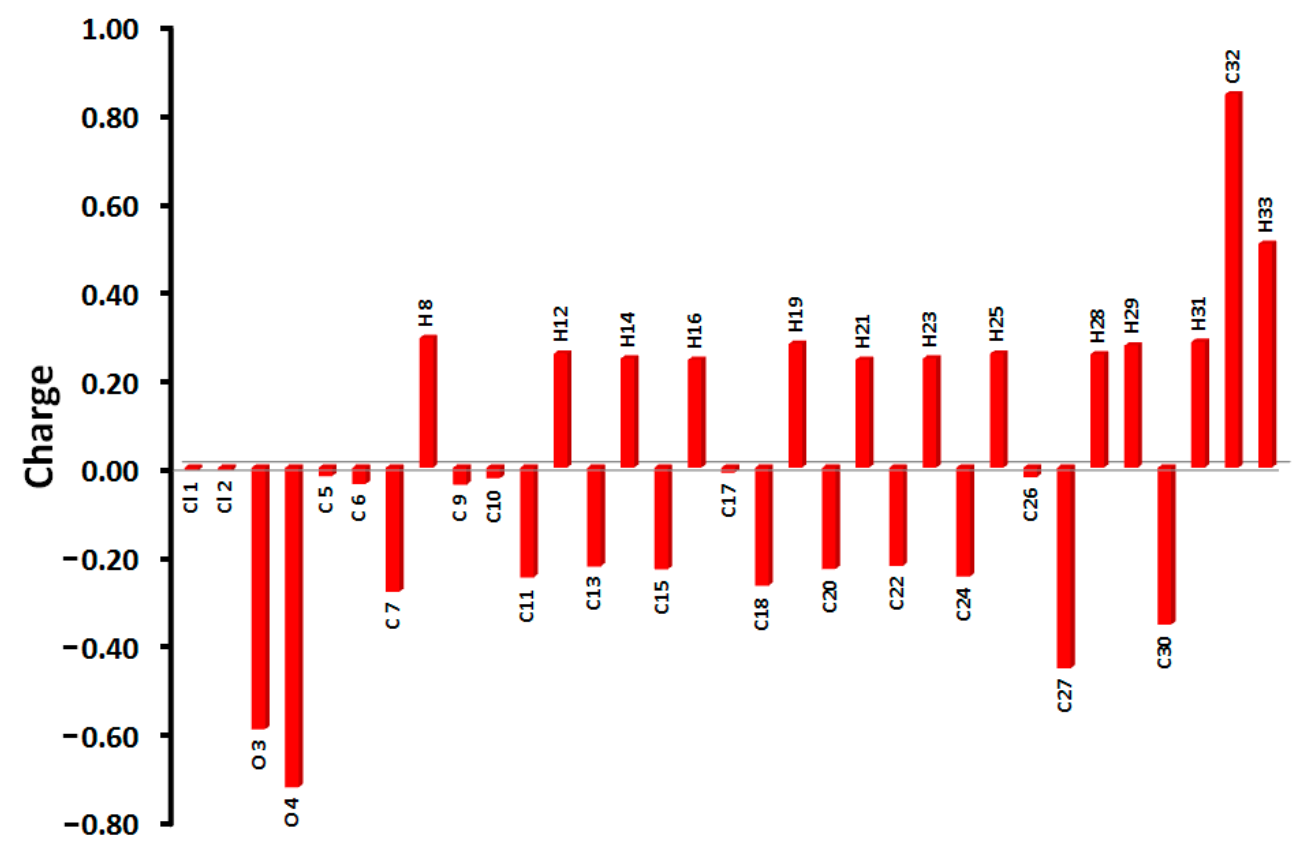

Figure 8. Natural atomic charge populations for 5.
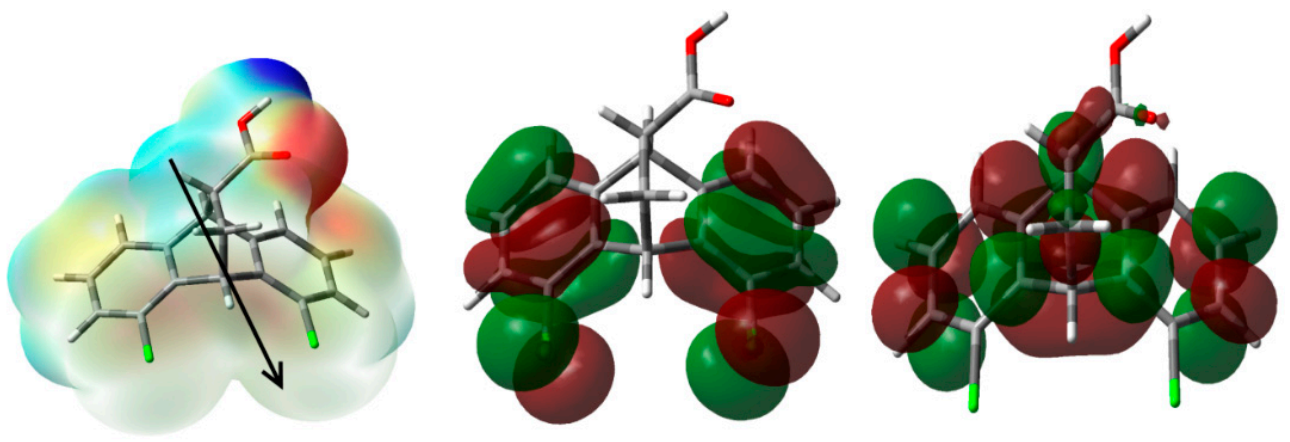

Figure 9. The MEP, HOMO and LUMO of 5.

Figure 9 presents the HOMO and LUMO levels of the studied compound 5. The $\pi$ system exists mainly in the studied compound; hence, the HOMO-LUMO intramolecular 
charge transfer could be portrayed as mainly $\pi-\pi^{*}$ excitation. The following indices were calculated, namely $\mathrm{I}=-\mathrm{E}_{\mathrm{HOMO}}$ (ionization potential), $\mathrm{A}=-\mathrm{E}_{\mathrm{LUMO}}$ (electron affinity), $\mu=-(\mathrm{I}+\mathrm{A}) / 2$ (chemical potential), $\eta=(\mathrm{I}-\mathrm{A}) / 2)$ (hardness), and $\omega=\mu^{2} / 2 \eta$ (electrophilicity) [40-45], giving values of $6.635,0.687,-3.661,5.948$, and $1.127 \mathrm{eV}$, respectively. It was believed that these electronic parameters play important roles in the biomolecular reactivity.

\subsection{NMR Spectra}

DFT calculations were also used to calculate the NMR spectra of 5 (Table S3, Supplementary Data). Indeed, the chemical shifts in the NMR spectra were computed and compared with the values obtained experimentally. The resulting straight line plots were found to have high correlation coefficients $\left(R^{2}\right)$. The $R^{2}$ values were 0.9884 and 0.9705 for the bond angles and distances, respectively, indicating harmony between the computed and experimental results (Figure 10).
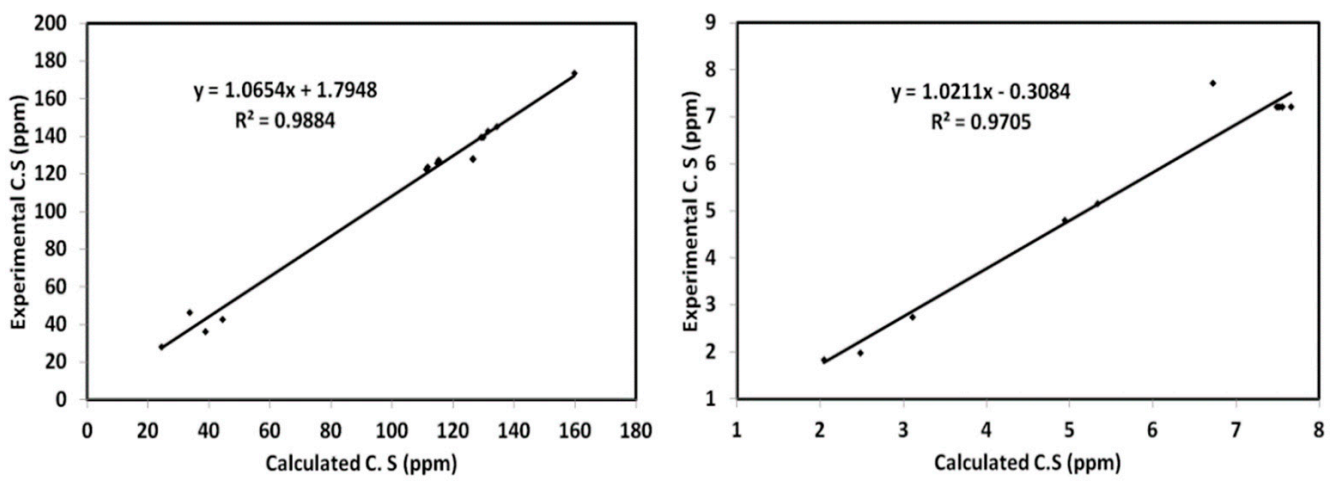

Figure 10. ${ }^{1} \mathrm{H}$ - and ${ }^{13} \mathrm{C}-\mathrm{NMR}$ diagrams, indicating harmony between the computed and experimental results.

\section{Conclusions}

In summary, the synthesis and single-crystal X-ray structure of 1,8-dichloro-9,10dihydro-9,10-ethanoanthracene-11-carboxylic acid were reported. The molecular structure of the studied compound was elcuidated via single-crystal X-ray diffraction analysis. Additionally, Hirshfeld calculations were computed and the electronic properties were assessed, such as the dipole moment, atomic charge, HOMO and LUMO levels and NMR spectra. The calculated NMR chemical shifts revealed a high level of harmony in the experimentally obtained results.

Supplementary Materials: The following are available online at https://www.mdpi.com/article/ 10.3390/cryst11101161/s1: Table S1-S3: The calculated geometric parameters, natural charges and nuclear magnetic resonance chemical shifts $\left({ }^{1} \mathrm{H}\right.$ - and $\left.{ }^{13} \mathrm{C}-\mathrm{NMR}\right)$ of the studied compound $\mathbf{5}$.

Author Contributions: M.S.A., A.B. and M.A.S. designed the study. S.M.S. carried out the computional study. S.Y. and I.A. carried out the X-ray diffraction analysis. I.S. and M.A.S. carried out the chemical analysis and methodology investigation. M.S.A. acquired funding. All authors helped in the writing, editing and approval of the final manuscript. All authors have read and agreed to the published version of the manuscript.

Funding: This research was funded by the Deanship of Scientific Research at Princess Nourah bint Abdulrahman University through the Fast-track Research Funding Program.

Acknowledgments: This research was funded by the Deanship of Scientific Research at Princess Nourah bint Abdulrahman University through the Fast-track Research Funding Program.

Conflicts of Interest: The authors declare no conflict of interest. 


\section{References}

1. Peng, L.; Yao, J.W.; Wang, M.; Wang, L.Y.; Huang, X.L.; Wei, X.F.; Ma, D.G.; Cao, Y.; Zhu, X.H. Efficient soluble deep blue electroluminescent dianthracenylphenylene emitters with CIE y $(\mathrm{y} \leq 0.08)$ based on triplet-triplet annihilation. Sci. Bull. 2019, 64, 774-781. [CrossRef]

2. Park, Y.H.; Shim, S.Y.; Seo, Y.; Lee, C.H. Organic Light Emitting Diode of High Efficiency. U.S. Patent 10,559,758, 11 February 2020.

3. Varol, S.F.; Sayin, S.; Eymur, S.; Merdan, Z.; Ünal, D. Optical performance of efficient blue/near UV nitropyridine-conjugated anthracene (NAMA) based light emitting diode. Org. Electron. 2016, 31, 25-30. [CrossRef]

4. Yu, Y.H.; Huang, C.H.; Yeh, J.M.; Huang, P.T. Effect of methyl substituents on the N-diaryl rings of anthracene-9, 10-diamine derivatives for OLEDs applications. Org. Electron. 2011, 12, 694-702. [CrossRef]

5. Chen, L.-Y.; Shiu, Y.J.; Wu, Y.J.; Huang, W.Y. Simple structured color tunable white organic light-emitting diodes utilizing an ambipolar anthracene derivative with low-lying LUMO. Org. Electron. 2020, 76, 105454. [CrossRef]

6. Lee, A.H.; Jang, Y.; Kim, G.H.; Kim, J.J.; Lee, S.S.; Ahn, B.J. Decolorizing an anthraquinone dye by Phlebia brevispora: Intra-species characterization. Eng. Life Sci. 2017, 17, 125-131. [CrossRef]

7. Xu, J.; Niu, G.; Wei, X.; Lan, M.; Zeng, L.; Kinsella, J.M.; Sheng, R. A family of multi-color anthracene carboxyimides: Synthesis, spectroscopic properties, solvatochromic fluorescence and bio-imaging application. Dyes Pigm. 2017, 139, 166-173. [CrossRef]

8. Wadler, S.; Fuks, J.Z.; Wiernik, P.H. Phase I and II agents in cancer therapy: I. Anthracyclines and related compounds. J. Clin. Pharmacol. 1986, 26, 491-509. [CrossRef]

9. Sunmonu, T.O.; Owolabi, O.D.; Oloyede, O.B. Anthracene-induced enzymatic changes as stress indicators in African catfish, Heterobranchus bidorsalis Geoffroy Saint Hilaire, 1809. Res. J. Environ. Sci. 2009, 3, 677-686.

10. McNamara, Y.; Bright, S.; Byrne, A.; Cloonan, S.; McCabe, T.; Williams, D.; Meegan, M. Synthesis and antiproliferative action of a novel series of maprotiline analogues. Eur. J. Med. Chem. 2014, 71, 333-353. [CrossRef]

11. Cloonan, S.M.; Drozgowska, A.; Fayne, D.; Williams, D.C. The antidepressants maprotiline and fluoxetine have potent selective antiproliferative effects against Burkitt lymphoma independently of the norepinephrine and serotonin transporters. Leuk. Lymphoma 2010, 51, 523-539. [CrossRef]

12. Cloonan, S.M.; Williams, D.C. The antidepressants maprotiline and fluoxetine induce Type II autophagic cell death in drugresistant Burkitt's lymphoma. Int. J. Cancer 2011, 128, 1712-1723. [CrossRef]

13. Huang, H.-S.; Chiu, H.-F.; Hwang, J.-M.; Jen, Y.-M.; Tao, C.-W.; Lee, K.-Y.; Lai, Y.-L. Studies on anthracenes. 2. Synthesis and cytotoxic evaluation of 9-acyloxy 1, 8-dichloroanthracene derivatives. Chem. Pharm. Bull. 2001, 49, 1346-1348. [CrossRef]

14. Huang, H.-S.; Lin, P.-Y.; Hwang, J.-M.; Tao, C.-W.; Hsu, H.-C.; Lai, Y.-L. Studies on anthracenes. 3. Synthesis, lipid peroxidation and cytotoxic evaluation of 10-substituted 1, 5-dichloro-9 (10H)-anthracenone derivatives. Chem. Pharm. Bull. 2001, 49, 1288-1291. [CrossRef]

15. Bitonti, A.J.; Sjoerdsma, A.; McCann, P.P.; Kyle, D.E.; Oduola, A.; Rossan, R.N.; Milhous, W.K.; Davidson, D.E. Reversal of chloroquine resistance in malaria parasite Plasmodium falciparum by desipramine. Science 1988, 242, 1301-1303. [CrossRef]

16. Alibert, S.; Santelli-Rouvier, C.; Pradines, B.; Houdoin, C.; Parzy, D.; Karolak-Wojciechowska, J.; Barbe, J. Synthesis and Effects on Chloroquine Susceptibility in Plasmodium f alciparum of a Series of New Dihydroanthracene Derivatives. J. Med. Chem. 2002, 45, 3195-3209. [CrossRef]

17. Szabó, D.; Szabó, G.; Ocsovszki, I.; Aszalos, A.; Molnár, J. Anti-psychotic drugs reverse multidrug resistance of tumor cell lines and human AML cells ex-vivo. Cancer Lett. 1999, 139, 115-119. [CrossRef]

18. Karama, U.; Sultan, M.A.; Almansour, A.I.; El-Taher, K.E. Synthesis of chlorinated tetracyclic compounds and testing for their potential antidepressant effect in mice. Molecules 2016, 21, 61. [CrossRef]

19. Barton, B.; Senekal, U.; Hosten, E.C. Comparing the host behavior of roof-shaped compounds trans-9, 10-dihydro-9, 10ethanoanthracene-11,12-dicarboxylic acid and its dimethyl ester in the presence of mixtures of xylene and ethylbenzene guests. CrystEngComm 2021, 23, 4560-4572. [CrossRef]

20. Wang, Y.; Ghanem, B.S.; Ali, Z.; Hazazi, K.; Han, Y.; Pinnau, I. Recent progress on polymers of intrinsic microporosity and thermally modified analogue materials for membrane-based fluid separations. Small Struct. 2021, 2, 2100049. [CrossRef]

21. Li, M.; Zhou, Y.; Yao, Y.; Gao, T.; Yan, P.; Li, H. Designing the water-quenching resistant high luminescent europium complexes by regulating the orthogonal arrangement of bis- $\beta$-diketone ligands. Dalton Trans. 2021, 50, 9914-9922. [CrossRef]

22. Fyfe, T.J.; Scammells, P.J.; Lane, J.R.; Capuano, B. Enantioenriched positive allosteric modulators display distinct pharmacology at the dopamine $\mathrm{D}_{1}$ receptor. Molecules 2021, 26, 3799. [CrossRef]

23. Karama, U.S.; Sultan, M.A.; Almansour, A.I.; Tahir, K.E.; Elnakady, Y.A.; Mahaya, T.A. Halogenated Tetracyclic Compounds. U.S. Patent No. 9498460B1, 22 November 2016.

24. Sultan, M.A.; Almansour, A.I.; Pillai, R.R.; Kumar, R.S.; Arumugam, N.; Armaković, S.; Armaković, S.J.; Soliman, S.M. Synthesis, theoretical studies and molecular docking of a novel chlorinated tetracyclic:(Z/E)-3-(1, 8-dichloro-9, 10-dihydro-9, 10-ethanoanthracen-11-yl) acrylaldehyde. J. Mol. Struct. 2017, 1150, 358-365. [CrossRef]

25. Sultan, M.A.; Galil, M.S.A.; Al-Qubati, M.; Omar, M.M.; Barakat, A. Synthesis, Molecular Docking, Druglikeness Analysis, and ADMET Prediction of the Chlorinated Ethanoanthracene Derivatives as Possible Antidepressant Agents. Appl. Sci. 2020, 10, 7727. [CrossRef] 
26. Al-Qubati, M.; Ghabbour, H.A.; Soliman, S.M.; Al-Majid, A.M.; Barakat, A.; Sultan, M.A. Synthesis of N-(anthracen-9-ylmethyl)$N$-methyl-2-(phenylsulfonyl)ethanamine via microwave green synthesis method: $\mathrm{X}$-ray characterization, DFT and Hirshfeld analysis. Crystals 2020, 10, 643. [CrossRef]

27. Sultan, M.A.; Galil, M.S.; Al-Qubati, M.; Al-Majid, A.M.; Barakat, A. Microwave-assisted regioselective synthesis of substituted9-bromo-9, 10-dihydro-9, 10-ethanoanthracenes via Diels-Alder cycloaddition. J. King Saud Univ. Sci. 2020, 32, 3417-3420. [CrossRef]

28. Turner, M.J.; McKinnon, J.J.; Wolff, S.K.; Grimwood, D.J.; Spackman, P.R.; Jayatilaka, D.; Spackman, M.A. Crystal Explorer17 2017, University of Western Australia. Available online: http:/ / hirshfeldsurface.net (accessed on 12 June 2017).

29. Frisch, M.J.; Trucks, G.W.; Schlegel, H.B.; Scuseria, G.E.; Robb, M.A.; Cheeseman, J.R.; Scalmani, G.; Barone, V.; Mennucci, B.; Petersson, G.A.; et al. GAUSSIAN 09; Revision A02; Gaussian Inc.: Wallingford, CT, USA, 2009.

30. Dennington, R., II; Keith, T.; Millam, J. (Eds.) GaussView; Version 4.1.; Semichem Inc.: Shawnee Mission, KS, USA, 2007.

31. Reed, A.E.; Curtiss, L.A.; Weinhold, F. Intermolecular interactions from a natural bond orbital, donor-acceptor viewpoint. Chem. Rev. 1988, 88, 899-926. [CrossRef]

32. Marten, B.; Kim, K.; Cortis, C.; Friesner, R.A.; Murphy, R.B.; Ringnalda, M.N.; Sitkoff, D.; Honig, B. New Model for Calculation of Solvation Free Energies: Correction of Self-Consistent Reaction Field Continuum Dielectric Theory for Short-Range HydrogenBonding Effects. J. Phys. Chem. 1996, 100, 11775-11788. [CrossRef]

33. Tannor, D.J.; Marten, B.; Murphy, R.; Friesner, R.A.; Sitkoff, D.; Nicholls, A.; Ringnalda, M.; Goddard, W.A.; Honig, B. Accurate first principles calculation of molecular charge distributions and solvation energies from ab initio quantum mechanics and continuum dielectric theory. J. Am. Chem. Soc. 1994, 116, 11875-11882. [CrossRef]

34. Cheeseman, J.R.; Trucks, G.W.; Keith, T.A.; Frisch, M.J. A Comparison of Models for Calculating Nuclear Magnetic Resonance Shielding Tensors. J. Chem. Phys. 1996, 104, 5497-5509. [CrossRef]

35. Wilhelm, M.; Schmidt, P. Synthese und eigenschaften von 1-aminoalkyl-dibenzo[b, e]bicyclo[2.2.2]octadienen. Helv. Chim. Acta 1969, 52, 1385-1395. [CrossRef]

36. Koteswar Rao, Y.; Nagarajan, M. Diels-Alder reactions of 1,1-bis[benzenesulfonyl]ethene. Synthesis 1984, 9, 757-758.

37. Burrows, L.; Masnovi, J.; Baker, R.J. [2,3:5,6]Dibenzo[2.2.2]octa-2,5,7-triene (C2/c) and [2,3:5,6]dibenz [2.2.2]octa-2, 5-diene. Acta Crystallogr. C Cryst. Struct. Commun. 1999, 55, 236-239. [CrossRef]

38. Simpson, M.; Storey, J.M.; Harrison, W.T. Diethyl 9,10-endo-ethano-9,10-dihydroanthracene-11,11-dicarboxylate. Acta Crystallogr. Sect. E Struct. Rep. Online 2004, 60, o1081-o1083. [CrossRef]

39. Kitamura, M.; Gao, G.; Nakajima, K.; Takahashi, T. Unusual Conformational Isomer of 9,10-Dihydro-1,2,3,4,5,6,7,8octapropylanthracene in Solid State. Chem. Lett. 2002, 31, 1076-1077. [CrossRef]

40. Foresman, J.B.; Frisch, Æ. Exploring Chemistry with Electronic Structure Methods, 2nd ed.; Gaussian: Pittsburgh, PA, USA, 1996.

41. Chang, R. Chemistry, 7th ed.; McGraw-Hill: New York, NY, USA, 2001.

42. Kosar, B.; Albayrak, C. Spectroscopic investigations and quantum chemical computational study of (E)-4-methoxy-2-[(ptolylimino) methyl] phenol. Spectrochim. Acta 2011, 78, 160-167. [CrossRef]

43. Koopmans, T.A. Ordering of wave functions and eigenenergies to the individual electrons of an atom. Physica 1933, 1, 104-113. [CrossRef]

44. Parr, R.G.; Yang, W. Density-Functional Theory of Atoms and Molecules; Oxford University Press: New York, NY, USA, 1989.

45. Parr, R.G.; Szentpaly, L.V.; Liu, S. Electrophilicity index. J. Am. Chem. Soc. 1999, 121, 1922-1924. [CrossRef] 